\title{
Micro-Crystalline Aluminide Coating Deposited on Fe-5Cr-Mo Steel by Vibrating Electro-Pulse Discharge
}

\author{
Jing $\mathrm{Ma}^{1,2}$, Yedong $\mathrm{He}^{1}$, Deren Wang ${ }^{1,3}$ and Wei Gao ${ }^{3 . *}$ \\ 'Beijing Key Laboratory for Corrosion, Erosion and Surface Technology. \\ University of Science and Technology Beijing, Beijing, 100083 China \\ ${ }^{2}$ School of Material, Hebei University of Science and Technology, \\ Shijiazhuang, 050054 China \\ ${ }^{3}$ School of Engineering, the University of Auckland, New Zealand
}

(Received November 5, 2003)

\begin{abstract}
Fe-Al intermetallic coatings of $100 \mu \mathrm{m}$ thickness were deposited on the surface of $\mathrm{Fe}-5 \mathrm{Cr}$-Mo steel samples by vibrating electro-pulse discharging. The coatings developed micro-crystalline structure due to the high cooling and solidification rate during deposition. The coatings also possess a strong metallurgical bonding to the steel substrate. Oxidation behaviour of these coated samples was investigated at $600^{\circ} \mathrm{C}$ in air for $200 \mathrm{~h}$. Sulfidation resistance was also studied in a flowing $\mathrm{SO}_{2}$ gas $(99.98 \%)$ at $600^{\circ} \mathrm{C}$. The results indicated that the oxidation and sulfidiation resistance of $\mathrm{Fe}-5 \mathrm{Cr}$-Mo steel hâs been greatly improved by the aluminide coatings. The oxidation mechanisms of the coatings are studied based on SEM and XRD analysis.
\end{abstract}

Key words: Vibrating electro-pulse deposition, Microcrystalline aluminide coating. $\mathrm{Fe}-5 \mathrm{Cr}-\mathrm{Mo}$ steel, Oxidation, Sulfidation.

\section{INTRODUCTION}

Surface modification can significantly improve the performance of a work piece and prolong its service life under harsh environments. Among various coating processes, aluminide coatings are widely used to provide high temperature protection for iron, nickel, and cobalt-based alloys /1-4/. Conventional processing routes for aluminide coatings include pack cementation, hot dip aluminizing and chemical vapor deposition (CVD). These methods have their shortcomings. For instance, pack cementation uses a large amount of powder, which is environmentally unfriendly and expensive. The size of the crucibles and furnace often limit the application of hot dip aluminizing and pack cementation. As for the CVD method, the deposition efficiency is usually low and the fabrication cost is high. Furthermore, these techniques cannot be used to treat a part or component in-situ.

Electro-pulse (spark) deposition (ESD) is a convenient technique to overcome the above problems. It uses the electrical energy stored in the capacitors to generate electric sparks between the anode and cathode. The high temperature generated by the spark produces partial melting of the electrode and substrate materials. The thin layer of molten material solidifies rapidly to form a micro-crystalline coating with good bonding to the substrates. ESD can be applied to any size of work pieces at the engineering spot. The equipment and operation method are simple and easy $15-9 \%$. The main shortcoming of this technique, however, has been the

\footnotetext{
' Corresponding author, e-mail: wgao@auckland.ac.nz
} 
low deposition rate and the difficulty of obtaining a thick coating.

This paper reports our study on the processing technique of a vibrating electro-pulse discharger in order to obtain a thick coating, and the performance of aluminide coatings deposited by this method. $\mathrm{Fe}-5 \mathrm{Cr}$ Mo steel was used as the coating substrate.

\section{EXPERIMENTAL METHODS}

Fe-5Cr-Mo steel specimens were cut to a size of $20 \times 15 \times 3 \mathrm{~mm}$. All surfaces of the specimens were ground to 600 -grit $\mathrm{SiC}$ paper and then cleaned ultrasonically in de-ionized water and alcohol.

The vibrating electro-pulse deposition equipment is schematically shown in Fig. I. Electromagnetic force was generated when $50 \mathrm{~Hz}$ alternating current was passed through the loop of the electromagnets. The electromagnetic force periodically attracted the iron plate, which held the aluminium electrode. In this way, the Al electrode contacted with the sample and discharge took place periodically, partially melting the electrode and sample surface. The molten $\mathrm{Al}$ and sample then solidified on the surface of the steel, forming an aluminide coating. Ar gas flowed at the tip of the electrode to avoid oxidation. An a.c. source of a welding machine was used to provide a voltage of $30-$ $35 \mathrm{~V}$. In order to obtain a dense coating, depositing was performed on a sample twice.
High temperature oxidation of the coated specimens was carried out in a furnace at $600^{\circ} \mathrm{C}$ in air for $200 \mathrm{~h}$. The specimens were weighed with an electronic balance with an accuracy of $10^{-5} \mathrm{~g}$ after every $10 \mathrm{~h}$ exposure. Oxidation kinetics curves were plotted using both mass gain and spallation mass-loss $v s$. exposure time.

High temperature sulfidation of the specimens was performed in flowing gas of $99.98 \% \mathrm{SO}_{2}$ at $600^{\circ} \mathrm{C}$ for $50 \mathrm{~h}$. The specimens were weighed before and after exposure, and the mass gain and spallation were measured accordingly.

Scanning electron microscopy (SEM) was used to observe the surface morphology of the oxide scales and to make an elemental map of cross-section after oxidation for $200 \mathrm{~h}$ and sulfidation for $50 \mathrm{~h}$ at $600^{\circ} \mathrm{C}$. The composition and phases of the corrosion products were analyzed by EDS and XRD.

\section{EXPERIMENTAL RESULTS}

Figure 2 shows the surface and cross-section morphology of coatings produced by vibrating electropulse deposition. It can be seen that the grains of the aluminide coatings are very small $(<1 \mu \mathrm{m})$; and the thickness of the coating is larger than $100 \mu \mathrm{m}$. There is no obvious boundary between the coating and the substrate, evidence of a good metallurgical bonding. EDS analysis shows that the main contents of the coatings are $\mathrm{Fe}$ and $\mathrm{Al}$, with a small amount of $\mathrm{Cr}$ (Fig. 3). No oxygen could be detected, indicating good

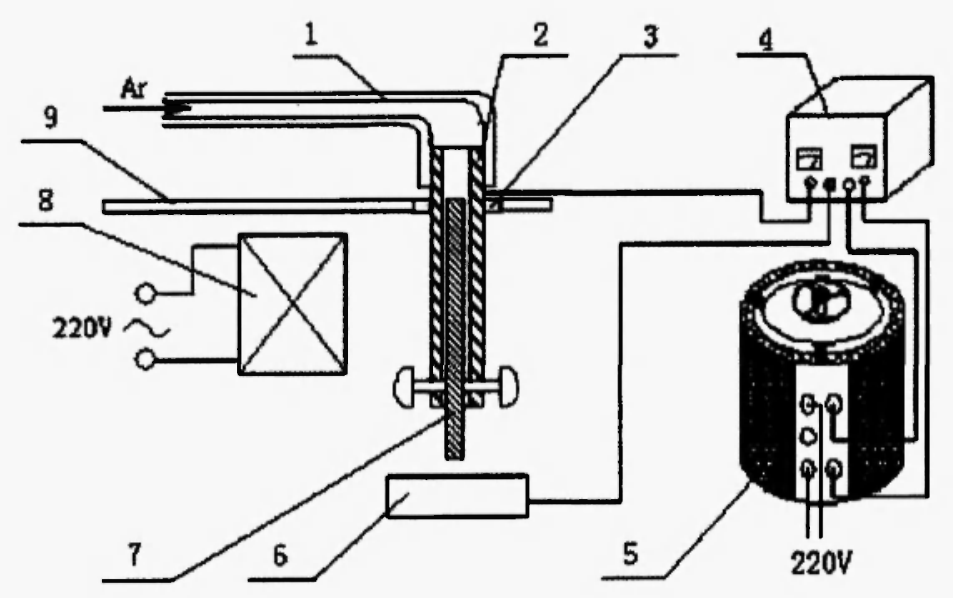

Fig. 1: Vibrating electro-pulse deposition equipment: 1. Ar tube. 2. Cu tube, 3. Insulating cushion, 4. An a.c. welding machine, 5. Booster, 6. Specimen, 7. Al electrode, 8. A loop, and 9. An iron plate. 

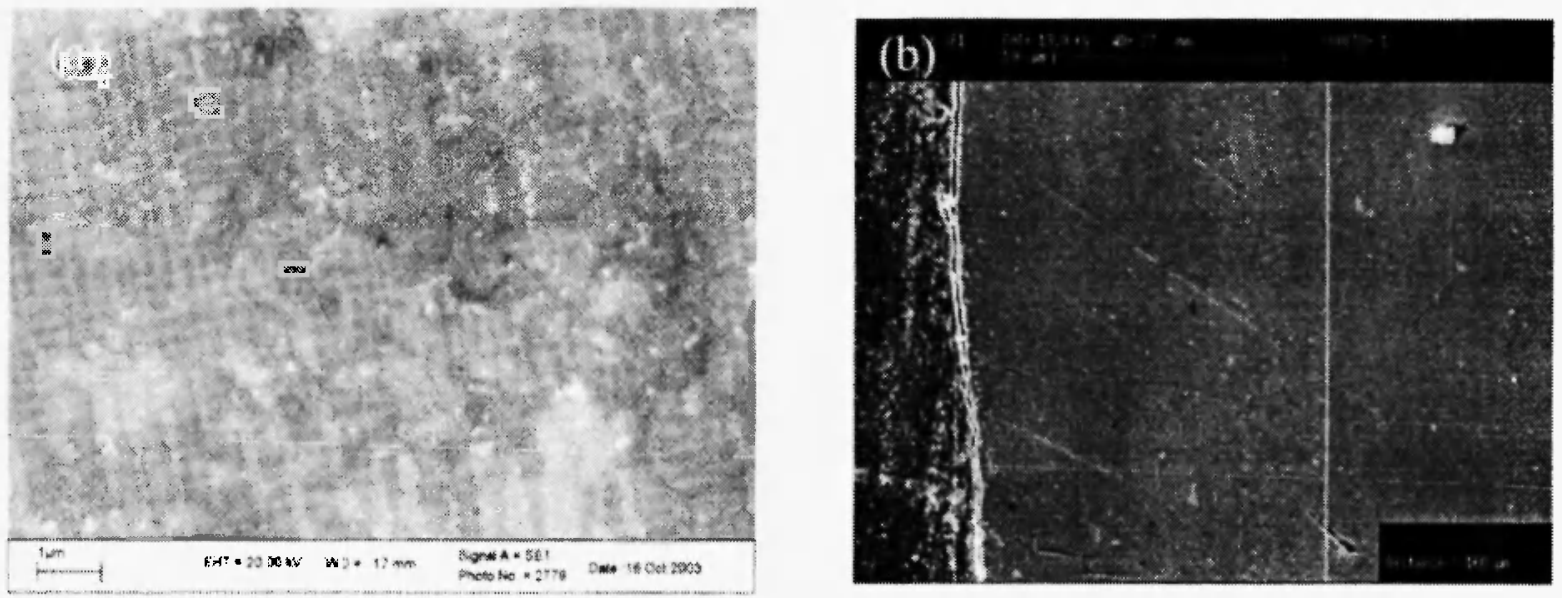

Fig. 2: SEM surface and cross-section morphologies of an aluminide coating: (a) Surface morphology, (b) crosssection morphology.

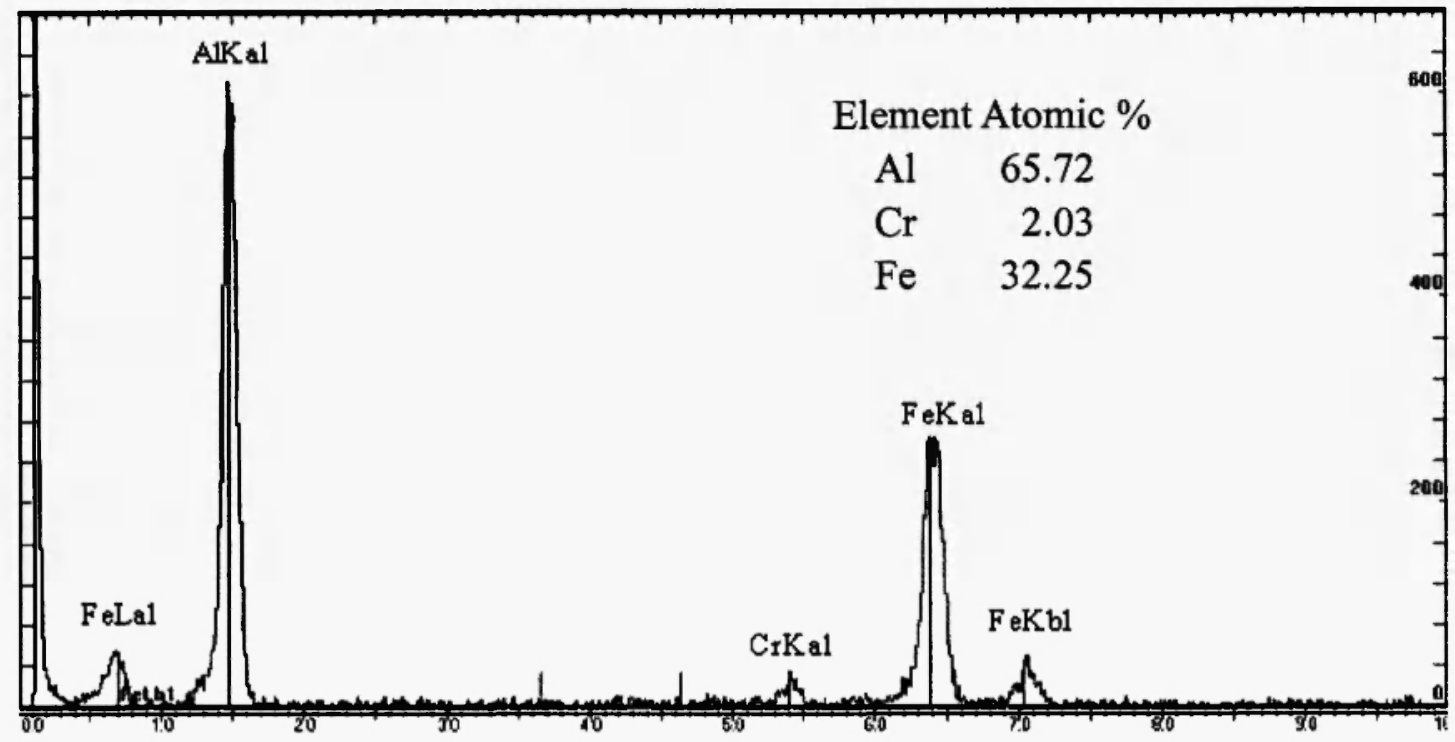

Fig. 3: EDS analysis of aluminide coating.

protection by the flowing Ar gas during deposition.

Figure 4 a shows the oxidation kinetics of $\mathrm{Fe}-5 \mathrm{Cr}$ Mo steel in air at $600^{\circ} \mathrm{C}$. It can be seen that the oxidation resistance of the steel has been improved significantly by the aluminide coatings. The specimen without coating produced a mass gain of $-4 \mathrm{mg} / \mathrm{cm}^{2}$ after oxidation at $600^{\circ} \mathrm{C}$ for $200 \mathrm{~h}$ in air, while the specimens with aluminide coatings showed mass gains of $0.3-0.4 \mathrm{mg} / \mathrm{cm}^{2}$. The spallation resistance was also improved by the coatings, from the uncoated steel of $0.15 \mathrm{mg} / \mathrm{cm}^{2}$ to the coated samples of $\sim 0.06 \mathrm{mg} / \mathrm{cm}^{2}$ as shown in Fig. 4b. therefore, aluminide coatings showed significant improvement to the oxidation resistance. The results also indicated that the deposition voltages ( 30 or $35 \mathrm{~V}$ ) did not have a significant effect on the properties.

The results of sulfidation are shown in Fig. 5. After exposure in $\mathrm{SO}_{2}$ at $600^{\circ} \mathrm{C}$ for $50 \mathrm{~h}$, the mass gain and spallation mass of the samples with aluminide coatings 

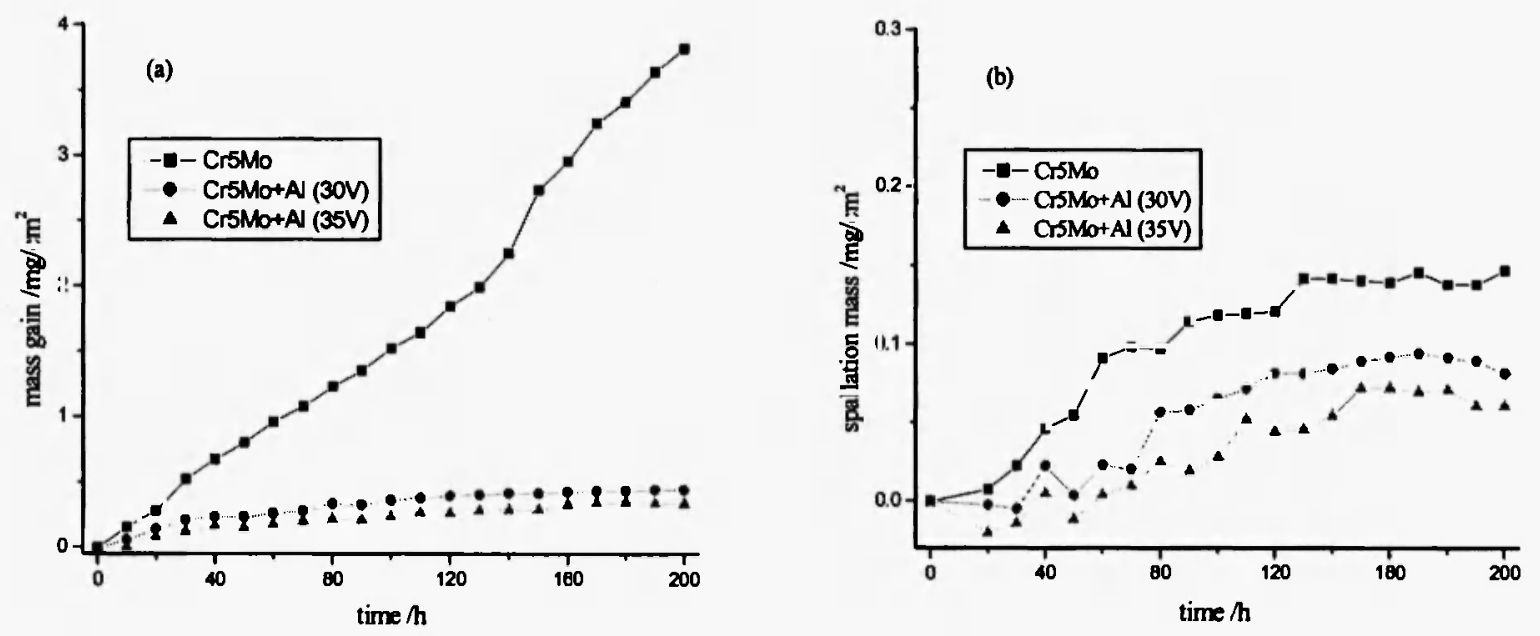

Fig. 4: Oxidation kinetics at $600^{\circ} \mathrm{C}$ in air for $200 \mathrm{~h}$; the samples were deposited with aluminide coatings: (a) mass gain vs time, and (b) oxide spallation vs time.
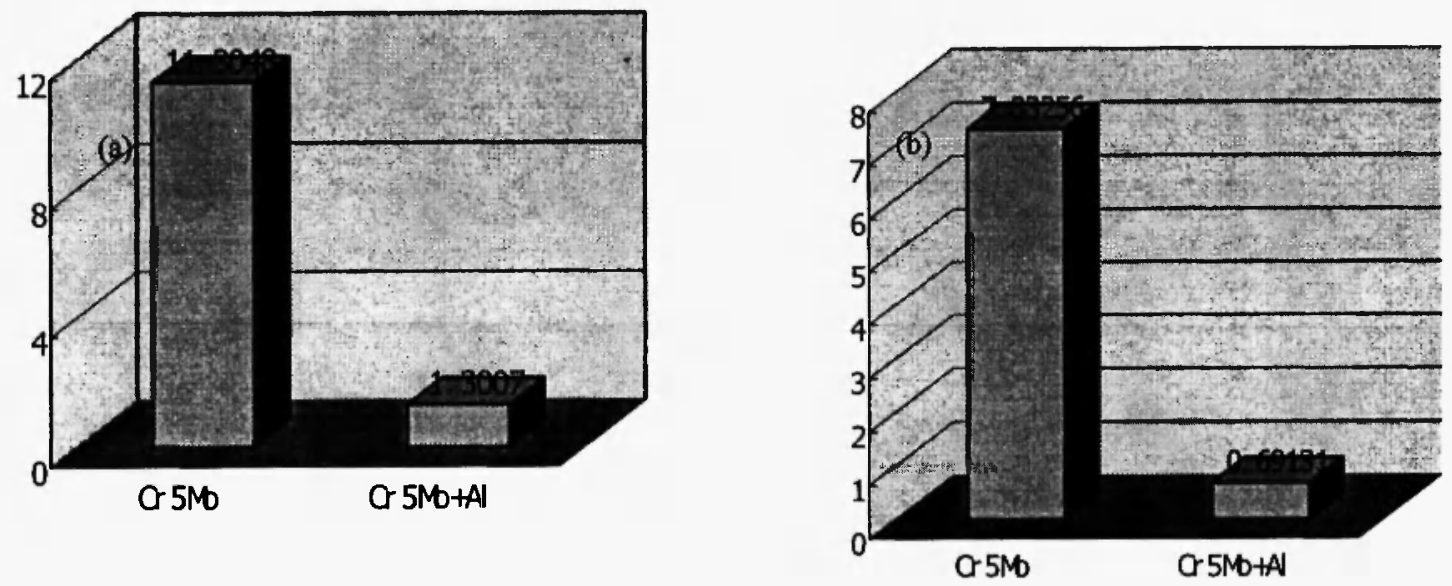

Fig. 5: Sulfidation experiment results at $600^{\circ} \mathrm{C}$ in $\mathrm{SO}_{2}$ for $50 \mathrm{~h}$ : (a) mass gain vs time, and (b) spallation vs time.

is only about $1 / 10$ of the steel. Even the colour of the samples is different: The steel samples showed a brown colour, while the coatings kept a metallic sheen. The sulfidation resistance of the aluminide coatings has also been significantly improved.

The SEM surface morphology of the oxide scales after oxidation and sulfidation is shown in Fig. 6. It is interesting to see that the oxide scale formed on $\mathrm{Fe}-5 \mathrm{Cr}$ Mo samples exhibits a whisker shape. The width of the whisker is smaller than $100 \mathrm{~nm}$ and the maximum length is about $10 \mu \mathrm{m}$. The formation of this type of whisker oxide leads to a high mass gain, but relatively low scale spallation, perhaps because the whiskershaped oxides do not break from the scale layer by layer.

The grains of the aluminide coating after oxidation are fine and smaller than $\mathrm{I} \mu \mathrm{m}$, while the grains after sulfidation show a nano-structure. Neither scales show scale spallation. Figure 7 shows the elemental distribution maps of the cross-section coating after oxidation at $600^{\circ} \mathrm{C}$ for $200 \mathrm{~h}$. It can be seen that Al was rich in the coating, and the thickness of the coatings was about 100 

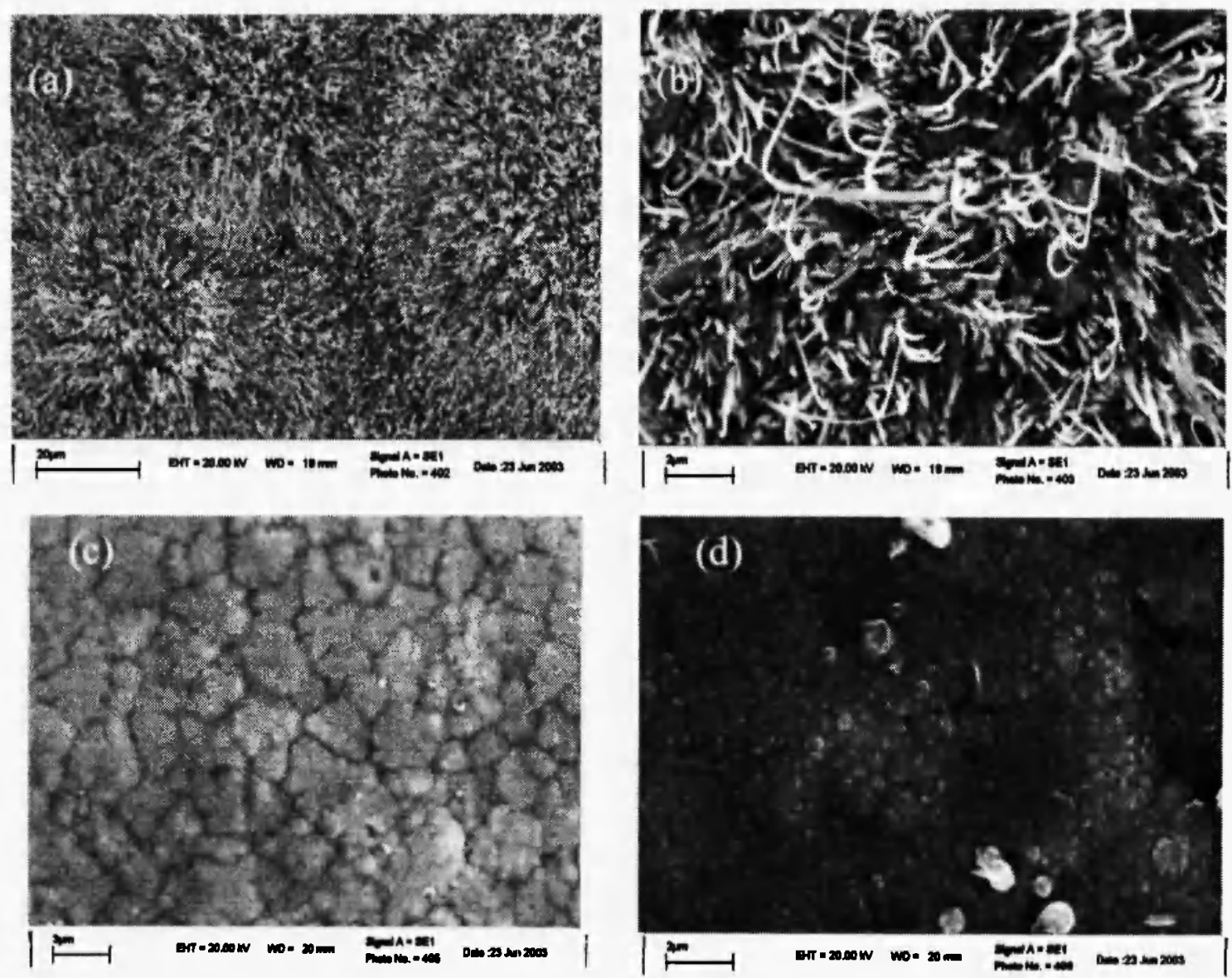

Fig. 6: SEM surface morphologies after oxidation and sulfidation at $600^{\circ} \mathrm{C}$ : (a) uncoated steel, (b) high magnification of (a), (c) aluminide coating after oxidation, and (d) aluminide coating after sulfidation.

$\mu \mathrm{m}$.

Figure 8 shows the XRD spectra of three types of specimens after oxidation in air at $600^{\circ} \mathrm{C}$ for $200 \mathrm{~h}$ and sulfidation in $\mathrm{SO}_{2}$ at $600^{\circ} \mathrm{C}$ for $50 \mathrm{~h}$. The oxide scales formed on the surface of Fe-5Cr-Mo steel was mainly composed of $\mathrm{Fe}, \mathrm{O}_{3}$ and $\mathrm{Cr}_{2} \mathrm{O}_{3}$, while the surfaces of aluminide coatings mainly show $\mathrm{Fe}-\mathrm{Al}$ intermetallic compound, indicating the aluminide coatings have been formed by vibrating electro-pulse deposition; and the formation of $\mathrm{Fe}$ and $\mathrm{Cr}$ oxides was suppressed.

\section{DISCUSSION}

Electro-pulse deposition techniques were developed using a special power supply /6-9/. Capacitance and resistance of the power supply can be adjusted to change the pulse frequency and discharging energy of each pulse. Alloy, aluminide or alloy-oxide composite coatings have been deposited on the surface of metal samples. However, the deposition efficiency is generally low due to the interaction of electrode and surface. The thickness of aluminide coatings is generally lower than $40 \mu \mathrm{m}$.

The improved ESD equipment uses a loop to create electromagnetic force to drive a vibrating electrode. An industrial a.c. power supply with $50 \mathrm{~Hz}$ frequency is suflicient for deposition operation. This power source permits a large current to pass, so that the energy of one pulse can be quite high. Moreover, Ar gas can protect the oxidation of coating during deposition. As a result, an aluminide coating about $100 \mu \mathrm{m}$ thick can be deposited on the steel surface, and the deposition efficiency is high. 


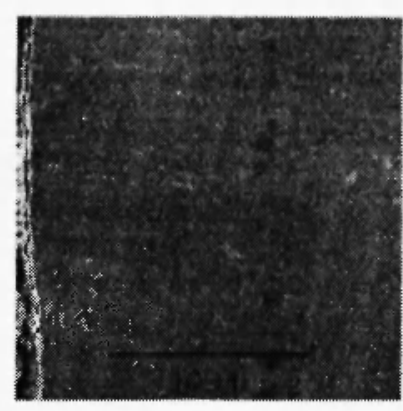

grey file:(1024X1024)

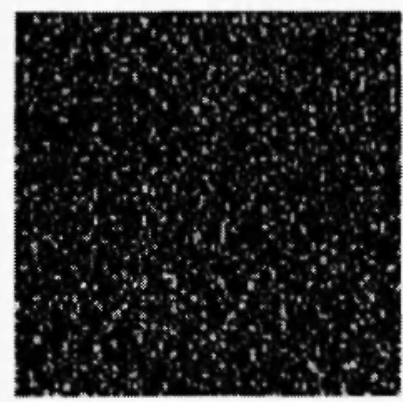

Mo(La1):(2138.2442)(128X128)

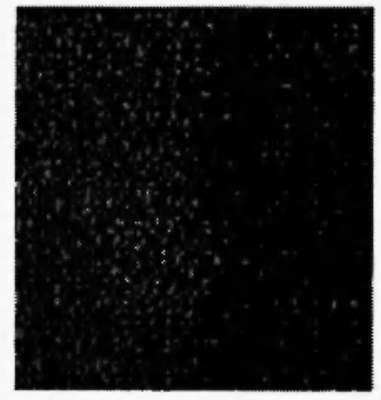

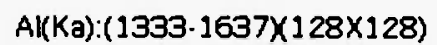

$\mathrm{Cr}(\mathrm{Ka}):(5262-5566)(128 \times 128)$

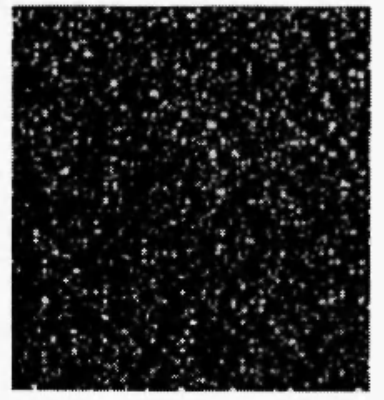

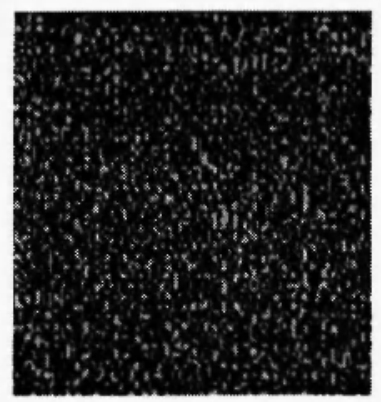

$\mathrm{Fe}(\mathrm{Ka}):(6251-6553)(128 \times 128)$

Fig. 7: SEM element mapping of the cross-section of Fe-5Cr-Mo steel with aluminide coating after oxidation at $600^{\circ} \mathrm{C}$ for $200 \mathrm{~h}$.

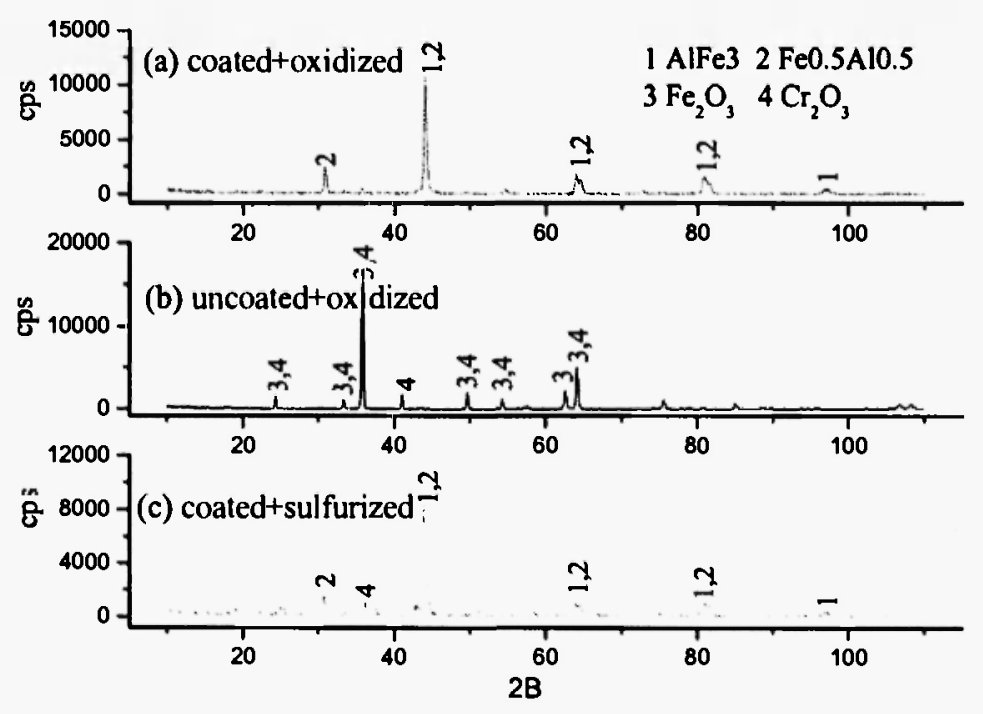

Fig. 8: XRD spectra of the specimens after oxidation and sulfidation at $600^{\circ} \mathrm{C}$ (a) coating after oxidation. (b) steel after oxidation, and (c) coating after sulfidation. 
The aluminide coating has significantly improved the high temperature corrosion resistance of the steel. The reasons can be suggested below:

1. The aluminide coating has a strong bonding to the steel substrate. It can stop the growth of $\mathrm{Fe}$-based oxide, avoiding fast high temperature corrosion. FeAl intermetallic compounds have good oxidation resistance, and can withstand oxidation up to $\sim 1200^{\circ} \mathrm{C}$, forming $\mathrm{Al}_{2} \mathrm{O}_{3}$ scale $/ 10-12 /$. The exposure temperature in the present tests was $600^{\circ} \mathrm{C}$. much lower than that level. Therefore, the $\mathrm{Al}$ oxide formed on the coating must be very thin, and is difficult to be detected by XRD.

2. Fe-Al intermetallic compounds also have excellent resistance to sulfidation in sulfur-containing atmosphere due to the fast formation and protection of a compact $\mathrm{Al}_{2} \mathrm{O}_{3}$ layer $/ 13 /$.

3. The coatings have micro-crystalline structure due to the high cooling and solidification rate. According to Wagner's oxidation theory $/ 14,15 /$, surface microcrystalline structure can effectively enhance the diffusion of the solute element in the alloy, thus promoting the formation of a selective oxide scale Therefore, micro-crystalline aluminide coatings possess excellent high temperature corrosion resistance.

\section{CONCLUSIONS}

The deposition efficiency of the newly-developed vibrating electro-pulse discharger is much improved compared to the conventional electro-pulse deposition. Micro-crystalline aluminide coatings of $100 \mu \mathrm{m}$ thick with metallurgical bonding to the substrate have been produced on steel samples by the vibrating electro-pulse deposition.

The aluminide coatings have micro-crystalline structure due to the fast solidification. Exposure tests indicated that these coatings possess superior oxidation and sulfidation resistance at $600^{\circ} \mathrm{C}$. SEM and XRD results indicated that the aluminide coatings can suppress the formation of Fe-based oxide. Microcrystalline structure promotes the formation of a protective oxide layer.
The vibrating electro-pulse coating technique has the advantages of simple and portable equipment, easy operation and high deposition rate. It is a potential method that can be used in-situ to improve high temperature corrosion resistance for steel parts.

\section{ACKNOWLEDGEMENT}

The work is supported by a grant of the Foundation for PhD Research from the Education Ministry of China (Grant No. 2000000815).

\section{REFERENCES}

1. P.S. Liu and K.M. Liang, Surface and Coatings Technology, 126, 64-68 (2000).

2. T.A. Kircher, B.G. McMordie and K. Richards, Surface and Coatings Technology, 108-109, 24-29 (1998).

3. A. Squillace, R. Bonetti, N.J. Archer and J.A. Yeatman, Surface and Coatings Technology, 120121, 118-123 (1999).

4. X.Y. Wang and D.Y. Li. Surface and Coatings Technology, 160, 20-28 (2002).

5. Q. Xu. Y. He, H. Qi, D. Wang, Z. Li and W. Gao, Materials Letters, 56, 85-92 (2002).

6. Y. He, H. Pang, H. Qi, D. Wang, Z. Li and W. Gao, Materials Science and Engineering, A334, 179-286 (2002).

7. H. Pang, H. Qi. Y. He, D. Wang and Z. Li, Science in China. 5, 540-546 (2000).

8. Z. Li, W. Gao, M. Yoshihara and Y. He, Materials Science and Engineering, A347, 243-252 (2003).

9. Z. Li, W. Gao and Y. He, Scripta Materialia, 45, 1099-1105 (2001).

10. C-H. Xu, W. Gaao and S. Li, Corrosion Science, 43. $671-688(2001)$

11. C-H. Xu. W. Gao and Y-D He, Scripta Materialia, 42, 975-980 (2000).

12. $\mathrm{C}-\mathrm{H} \mathrm{Xu}, \mathrm{W}$. Gao, M. Hyland and H. Gong, Corrosion Science, 43, 1891-1903 (2001). 
13. C-H Xu and W. Gao, High Temperature Materials and Processes, 18 (5-6), 3510363 (1999).

14. C. Wagner, Journal of the Electrochemical Society, 11, 627-633 (1956).

15. C. Wagner, Z. Elektrochem., 63, 772-782 (1959). 